\title{
ADAPTATION OF SINGAPORE DAISY (WEDELIA TRILOBATA) TO DIFFERENT ENVIRONMENTAL CONDITIONS; WATER STRESS, SOIL TYPE AND TEMPERATURE
}

\author{
AZEEM, A. ${ }^{1}-$ JAVED Q. ${ }^{1}-$ SUN, J. F. $.^{*}-$ ULLAH, I. $^{2}-$ KAMA, R. ${ }^{1}-$ DU, D. L. ${ }^{1,2^{*}}$ \\ ${ }^{1}$ School of the Environment and Safety Engineering, Jiangsu University, Zhenjiang 212013, \\ China \\ ${ }^{2}$ Key Laboratory of Modern Agricultural Equipment and Technology, Ministry of Education, \\ Institute of Agricultural Engineering, Jiangsu University, Zhenjiang, Jiangsu, China \\ *Corresponding authors \\ e-mail:ddl@ujs.edu.cn (D.L.Du), zxsjf@ujs.edu.cn (J.F.Sun) \\ (Received $18^{\text {th }}$ Dec 2019; accepted 22 $2^{\text {nd }}$ May 2020)
}

\begin{abstract}
Invasion success of the invasive plant species (Singapore daisy) mostly depends on environmental factors, therefore, this study was conducted to investigate the effect of temperature, $25 / 30{ }^{\circ} \mathrm{C}$ (outside), $30 / 35{ }^{\circ} \mathrm{C}$ (inside) and water fluctuation, volumetric water content at $100 \%$ field capacity (normal water), volumetric water content at 33\% field capacity (water stress) in three different soil types (nutrient soil, normal soil and sandy soil) on the growth and photosynthetic traits of Wedelia trilobata (Wt) in Jiangsu University, Zhenjiang China. In comparison, Wt significantly performed better in outside temperature at all water levels in every soil type. Wt can tolerate high temperature at normal water level in normal and nutrient soil. At outside temperature along with water stress in sandy soil, $\mathrm{Wt}$ exhibited reduction in growth and photosynthetic trails, but the adverse effect was more severe at inside temperature with water stress in normal and sandy soil. After $4^{\text {th }}$ week, leaf chlorophyll content of $\mathrm{Wt}$ decreased in water stress at outside and inside temperatures in normal and sandy soil. Furthermore, $\mathrm{Wt}$ maintained its water status under water stress, after the $4^{\text {th }}$ week to the $8^{\text {th }}$ week in every soil type, which indicated that Wt have the ability to grow in every harsh environmental condition. In conclusion $\mathrm{Wt}$ successfully invaded different soil types at high temperature, under water stress conditions.
\end{abstract}

Keywords: invasive plant species, resources variation, growth, physiological traits, invasion

\section{Introduction}

Invasive plant species are key threat to natural biodiversity and working of ecosystems (Schweiger et al., 2010). The properties that enhanced the ability of nonnative plants becoming invasive are linked with their fast germination to reproductive growth stage and their high phenotypic plasticity, all of these enable them to cope with different environmental stress habitats (Baker, 1974). Not all invasive plant species show these types of characteristics (Lorenzo et al., 2010). It is the knowledge about invasive plant species, namely why they become invasive and which properties within the plant help them to become invasive, that makes us clear how to control the spread of these invasive plant species. Invasion success of invasive plant species have been explained by several hypotheses i.e. novel-weapons hypotheses (Callaway et al., 2000), propagule-pressure hypotheses (Colautti et al., 2006; Adamowski et al., 2008; Pairon et al., 2010), increased competitive ability hypotheses (Blossey et al., 1995), high reproductive with dispersal success (Moravcova et al., 2010; Van Kleunen et al., 2015; Jacquemart et al., 2015) and enemy release hypothesis (Keane et al., 2002). Many of these proposed mechanisms were taking part in the invasion success of several invasive plant species. 
Invasive plant species have physiological, phenotypic plasticity and may utilize the resources for its growth development and reproduction, when the enemy pressure is reduced (Ebeling et al., 2008). According to these strategies invasive plant species should maintain their growth in poor resources environment and maximize their growth under favorable environmental conditions (Gioria et al., 2014). These strategies should be investigated with the help of physiological traits of invasive plant species under poor and favorable environmental conditions, in order to directly involve resource acquisition (Van Kleunen et al., 2010). Many physiological factors involved in plant growth development like net photosynthetic rate, growth rate, leaf species area (SLA) and water use efficiency (WUE) could help invasive plant species to improve their fitness in different environmental resources containing water fluctuation and temperature variations (Zheng et al., 2009; van Kleunen et al., 2011; Javed et al., 2019). These functional traits are vital for invasive plant species for reproductive and physiological evaluation to build new populations or maintain their population in different habitats (Sun et al., 2019). Therefore, the studies linked with invasive plant species and based on physiological traits could be helpful to understand their invasion success under different environmental conditions.

Biological invasion may increase due to climate change and fluctuation of environmental resources such as precipitation, nutrient variation, temperature and substrate type (Abatzoglou et al., 2011; Azeem et al., 2020). Among these water, soil type and temperature are the main factors in the development of invasive plant species in different type of habitats. Increased temperature helps to boost the expansion of invasive plant species under higher precipitation availability and better nutrient substrate (Wang et al., 2011). Soil nutrient composition and water holding capacity has been shown to have great influence on plant productivity and stability (Callaway et al., 2004; Middleton et al., 2012; Van Der Heijden et al., 2008). Interaction effect of soil type and water fluctuation have received more attention recently (van der Putten, 2010). Similarly, interaction of temperature variations and precipitation also played an important part in growth development and reproduction of invasive plant species (Saptiningsih et al., 2019). Therefore, it is important to study the effect of each environmental factor and their interaction related to the success of the target plant.

Singapore daisy (Wedelia trilobata, Wt) belongs to the Asteraceae family and an annual invasive plant species in China, was chosen for this study (Azeem et al., 2020). It has been registered as one of the top 100 worst invasive plant species in the world (Qi et al., 2014). In 1970s, Wt was introduced to south China as a groundcover plant, but it quickly spread to the field (Weber et al., 2008). Faster clonal growth is also an important feature for their successful invasion (Song et al., 2010). Wt has ability to survival in every habitat condition. It can bear high temperature and moderate drought under different soil types. It prefers to grow in nutrient rich soil and moderate temperature range with high amount of water (Dai et al., 2016). The competitive success of $\mathrm{Wt}$ partially depends on its reproductive capacities. According to reproductive biology, the competitive success depends upon its physiological traits that enhances both WUE and photosynthetic rate (Quinet et al., 2015). Many researchers have done work to check response of Wt under different moisture conditions, soil nutrient combination and shading conditions (Dai et al., 2016; Saptiningsih et al., 2019). Apart from this higher temperature, water fluctuation and soil culture are also very important factors restricting plant growth ( $\mathrm{Xu}$ et al., 2006). In addition, many researchers noted the response of invasive plant species with water stress and different 
temperature regime under only one type of soil (Legault II et al., 2018; Song, 2017), but none of them investigated the response of invasive plant species under combined effect of temperature variations along with water fluctuations in different soil types. Therefore, in this study our objectives were to investigate the response of Wt under water fluctuations and temperature variations within different soil types and their combined effect on physiological traits related to plant growth, water relation and their combination. Detailed physiological traits enable us to understand the invasion success of Wt under different environmental conditions. According to these we proposed hypotheses that $\mathrm{Wt}$ will grow better under normal water availability along with moderate temperature in every soil types but at severe temperature along with water stress, Wt sustain its growth in nutrient soil and normal soil due to their better water holding capacity and nutrient availability.

\section{Material and methods}

This study was conducted at the School of Environmental and Safety Engineering, Jiangsu University, Zhenjiang China $\left(32.20^{\circ} \mathrm{N}, 119.45^{\circ} \mathrm{E}\right)$. This study was started in May and completed in July 2019. Ramets of Singapore daisy (Wedelia trilobata, Wt) were collected outside of the greenhouse where they were grown for experimental studies. Ramets of $\mathrm{Wt}$ were prepared in the seedling trays with sand as a culture medium. These trays were placed in the greenhouse that had $25 \pm 5^{\circ} \mathrm{C}$ temperature with $70 \%$ relative humidity. When these ramets had two fully expended leaves, they were transferred into plastic pots (height $10 \mathrm{~cm}$, outer diameter $13 \mathrm{~cm}$ and lower inner diameter $6 \mathrm{~cm}$ ), filled with three type of soil (sandy soil, normal soil, and nutrient soil). The physical and chemical characteristics of all soil types, that were used in this study are given in Table 1.

Table 1. Physical and chemical characteristics of different soil types

\begin{tabular}{c|c|c|c|c}
\hline Parameters & Nutrient soil & Sandy soil & Normal soil & Unit \\
\hline $\mathrm{pH}$ & 7.0 & 6.60 & $6 . .20$ & - \\
Organic matter & 38 & 0.34 & 1.75 & $\%$ \\
Total nutrient & 3.8 & 0.98 & 1.6 & $\%$ \\
Water content & 20 & 15 & 18 & $\%$ \\
Electrical conductivity & 2 & 1.2 & 1.8 & $\mathrm{ds} / \mathrm{m}$ \\
\hline
\end{tabular}

These transferred seedlings were placed under different temperature conditions $25 / 30{ }^{\circ} \mathrm{C}$ and $30 / 35{ }^{\circ} \mathrm{C}$ named as inside and outside temperature regime. All these seedlings were watered normally for one week to adopt the inside and outside (temperature) conditions. After one week of seedling transfer, treatments were started. This study was completely spilt-plot design with temperature as whole plot factor and their factorial combination of water levels, soil types serve as split-plot factors (Will et al., 2013a) with five replicates $(2 \times 3 \times 2 \times 5), 60$ pots in total as shown in Figure 1 . The water treatment was set according to pot volumetric water content. Volumetric water content at $100 \%$ field capacity was taken as normal water treatment and volumetric water content at $33 \%$ field capacity was taken as water stress treatment. Soil moisture meter (TR-6/TR-6D, China) was used to measure volumetric soil water 
content three time a week and watering was carried out when the volumetric soil water content fell below the set treatment level.

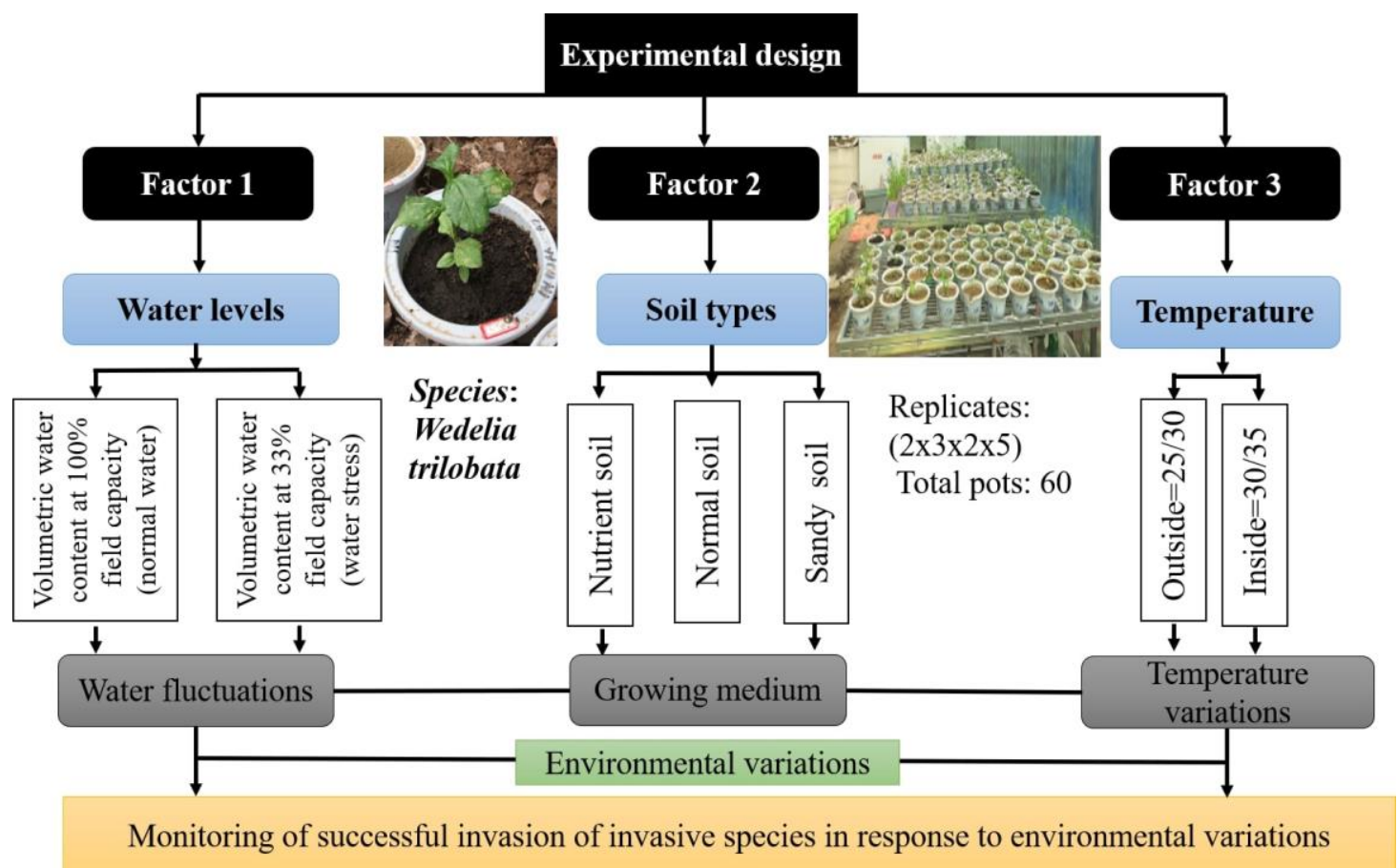

Figure 1. Experimental design

Set temperature values (outside and inside) were achieved in a greenhouse and the level of warming was controlled with ventilation (Valiño et al., 2014). The greenhouse at Jiangsu University, Zhenjiang, China was partitioned into two compartments in April 12 , 2017. One compartment was equipped with two ventilators $(380 \mathrm{~V}, 2000 \mathrm{~W})$, and two windows and it was used for the inside temperature regime (Teitel et al., 2010; Willits, 2003). The outside temperature group was placed under a shelter made of the same material of the greenhouse. The material of the greenhouse made by solar sheet, light transmittance up to $96 \%$ (Xiaoming et al., 2008; Ureña-Sánchez et al., 2012), thus without regards to shade. Air temperature and humidity were recorded automatically every 10 min using temperature humidity recorder (TH11R, Inste, Shenzhen, China) placed $5 \mathrm{~cm}$ above pot edge (Fang et al., 2015; Will et al., 2013b).

Outside and inside temperature condition were received two water levels (water stress) volumetric water content at $33 \%$ field capacity and (normal water) volumetric water content at $100 \%$ field capacity in all three types of soil. The details of the treatments were explained in Table 2. These treatments were continued for two month and parameters related to growth were determined after every week. The photosynthetic traits and water potential were determined after the $4^{\text {th }}$ and the $8^{\text {th }}$ week of the study period.

\section{Plant growth measurements}

The parameters selected for plant growth measurement were plant height, number of nodes, leaves per plant and specific leaf area (SLA). The plant height was determined from the top of the soil surface to the top of first leaf with a ruler. Leaf chlorophyll 
content was measured with portable chlorophyll meter (SPAD; Oakoch OK-Y104, China). Moisture content was measured with moisture meter (TR-6/TR-6D, China).

Leaf area was determined with ImageJ software, then these leaves, were placed into an oven at $60{ }^{\circ} \mathrm{C}$ for two days to determine their dry weight (DW). Specific leaf area (SLA) were determined as the ratio of leaf area to leaf DW.

Table 2. Experiment treatments detail

\begin{tabular}{c|c|c|c}
\hline Treatments & Soil type & Water level & Temperature \\
\hline $\mathrm{T}_{1}$ & Nutrient & Normal water & Outside \\
$\mathrm{T}_{2}$ & Normal & Normal water & Outside \\
$\mathrm{T}_{3}$ & Sandy & Normal water & Outside \\
$\mathrm{T}_{4}$ & Nutrient & Water stress & Outside \\
$\mathrm{T}_{5}$ & Normal & Water stress & Outside \\
$\mathrm{T}_{6}$ & Sandy & Water stress & Outside \\
$\mathrm{T}_{7}$ & Nutrient & Normal water & Inside \\
$\mathrm{T}_{8}$ & Normal & Normal water & Inside \\
$\mathrm{T}_{9}$ & Sandy & Normal water & Inside \\
$\mathrm{T}_{10}$ & Nutrient & Water stress & Inside \\
$\mathrm{T}_{11}$ & Normal & Water stress & Inside \\
$\mathrm{T}_{12}$ & Sandy & Water stress & Inside \\
\hline
\end{tabular}

Normal water representing pot volumetric water content at $100 \%$ field capacity, water stress representing pot volumetric water content at $33 \%$ field capacity. Outside temperature $=25 / 30{ }^{\circ} \mathrm{C}$, Inside temperature $=30 / 35^{\circ} \mathrm{C}$

\section{Photosynthetic traits}

Photosynthetic traits were determined after the $4^{\text {th }}$ and the $8^{\text {th }}$ week of the treatment's initiation. Gas exchange parameters like net photosynthetic rate $\left(\mathrm{P}_{\mathrm{N}}\right)$, stomatal conductance (gs), and transpiration ( $\mathrm{Tr}$ ) were recorded by using a portable photosynthesis measurement system (LI-6400XT, LI-COR, Lincoln, NE, USA). A fully extended leaf from the top of the plant was selected for measurement. Measurement were performed under full sunshine conditions from $10 \mathrm{am}$ to $11 \mathrm{am}$. The following conditions were maintained during the measurement: photosynthetically active radiation maximum up to $1000 \mu \mathrm{mol} \mathrm{m} \mathrm{s}^{-1}$, molar flow of air $403.3 \mathrm{mmol} \mathrm{m}^{-2} \mathrm{~s}^{-1}$, ambient $\mathrm{CO}_{2}$ concentration $400 \mu \mathrm{mol} \mathrm{mol}{ }^{-1}$, atmospheric pressure $99.9 \mathrm{kPa}$, water vapor pressure ranged from 7.0 to 8.8 mbar.

Water use efficiency was calculated according to the following equation:

$$
\text { WUE }=\mathrm{P}_{\mathrm{N}} / \mathrm{T}_{\mathrm{r}}
$$

where $\mathrm{P}_{\mathrm{N}}$ : net photosynthetic rate and Tr: transpiration respectively.

\section{Plant water status}

Plant water status was measured through water potential (Wp). Wp of every treatment plant was determined after the $4^{\text {th }}$ and the $8^{\text {th }}$ week of the treatment with the help of a dew point micro voltmeter in a C-52-SF universal sample room (Psypro, Wescor, USA). 


\section{Statistical analysis}

Variance analysis with four crossed fixed factors (water level, soil type, weeks, temperature) was performed to analyse soil moisture content, plant height, leaves per plant, nodes per plant and leaf chlorophyll content. Variance analysis with three crossed fixed factors (water level, soil type and temperature) was performed to analyse, gas exchange and water status parameters. Post hoc analyses were performed using the Tukey test with $\mathrm{p}<0.05$. All these analyses were performed on SPSS 22, software (SPSS Inc., Chicago, IL, USA). Origin pro 9.0 was used to makes graphs.

\section{Results}

\section{Growth response}

Water levels, temperature variations, soil types and duration of treatment significantly affect plant height as shown in Table 3. Their interactions also have significant effect on plant height $\left(\mathrm{F}_{12,126}=22.115, \mathrm{P}<0.01\right)$. Plant height at outside temperature $\mathrm{T}_{6}$ showed the smallest value while at inside temperature $\mathrm{T}_{11}$ and $\mathrm{T}_{12}$ both resulted in the smallest height as shown in Figure $2 A, B$.

Table 3. Analysis of variance with four fixed factors against growth response

\begin{tabular}{|c|c|c|c|c|c|}
\hline Responses & $\begin{array}{l}\text { Plant } \\
\text { height }\end{array}$ & $\begin{array}{c}\text { Moisture } \\
\text { content }\end{array}$ & $\begin{array}{c}\text { Leaves per } \\
\text { plant }\end{array}$ & $\begin{array}{c}\text { Nodes per } \\
\text { plant }\end{array}$ & $\begin{array}{c}\text { Leaf } \\
\text { chlorophyll } \\
\text { content }\end{array}$ \\
\hline Temperature & $1325.480^{* *}$ & $3176.878^{* * *}$ & $46.398^{* *}$ & $78.545^{* *}$ & 3.177 \\
\hline Soil type & $1770.225^{* *}$ & $2439.745^{* * *}$ & $199.150^{* *}$ & $72.591^{* *}$ & 1.286 \\
\hline Weeks & $5903.425^{* *}$ & $235.388^{* *}$ & $1071.506^{* *}$ & $516.460^{* *}$ & 10.764 \\
\hline Water level & $1021.544^{* *}$ & $1977.366^{* *}$ & $869.251^{* *}$ & $387.879^{* *}$ & 18.034 \\
\hline Temperature $*$ Soil type & $617.065^{* *}$ & $34.004^{* *}$ & $19.537^{* *}$ & .045 & .779 \\
\hline Temperature $*$ Weeks & $132.138^{* *}$ & $4.135^{*}$ & $3.313^{*}$ & $5.753^{* *}$ & .336 \\
\hline Temperature $*$ Water level & $194.239^{* *}$ & $50.821^{* * *}$ & $28.602^{* *}$ & $87.515^{* *}$ & 1.102 \\
\hline Soil type $*$ Weeks & $75.388^{* *}$ & $3.004^{*}$ & .372 & $7.982^{* *}$ & .675 \\
\hline Soil type $*$ Water level & $175.465^{* *}$ & $344.764^{* *}$ & $33.289^{* *}$ & $17.924^{* *}$ & .217 \\
\hline Weeks* Water level & $323.599^{* *}$ & .708 & $94.572^{* *}$ & $34.591^{* *}$ & $6.278^{* *}$ \\
\hline Temperature $*$ Soil type $*$ Weeks & $48.578^{* *}$ & $5.319^{* *}$ & $2.580^{*}$ & .806 & .893 \\
\hline Temperature $*$ Soil type $*$ Water level & $395.196^{* *}$ & $96.140^{* *}$ & $7.961^{* *}$ & $9.561^{* * *}$ & 2.610 \\
\hline Temperature $*$ Weeks $*$ Water level & $23.958^{* *}$ & $7.267^{* *}$ & 1.469 & $4.753^{* *}$ & 1.103 \\
\hline Soil type $*$ Weeks $*$ Water level & $20.000^{* *}$ & 1.105 & $10.261^{* *}$ & 1.538 & 1.439 \\
\hline Temperature $*$ Soil type $*$ Weeks $*$ Water level & $22.115^{* *}$ & .736 & $2.104^{*}$ & 1.412 & .630 \\
\hline
\end{tabular}

Main and interactive effects (F-values) of water levels, temperature, soil type and weeks on the growth parameters of Wedelia trilobata over the growing period. ** and * indicate a significant level at $\mathrm{P}<0.01$ and $\mathrm{P}<0.05$

Soil moisture content was also significantly effective on temperature $\left(\mathrm{F}_{1,126}=3176.878, \quad \mathrm{P}<0.01\right)$, soil types $\left(\mathrm{F}_{2,84}=2439.745, \quad \mathrm{P}<0.01\right)$, weeks $\left(\mathrm{F}_{6}\right.$, $\left.{ }_{36}=235.388, \mathrm{P}<0.01\right)$, and water levels $\left(\mathrm{F}_{1,126}=1977.366, \mathrm{P}<0.01\right)$. Interaction effect between weeks and water levels were non-significant due to soil moisture content depends upon soil type and its water holding capacity as shown in Table 3. The interaction effect of temperature, soil types, weeks and water levels were nonsignificant $\left(F_{12,126}=0.736, P=0.715\right)$. Soil moisture content at $T_{6}$ and at $T_{11}$ and $T_{12}$ shown lower values as compared to other treatment levels with increasing the duration of treatment period as shown in Figure $2 C, D$. 

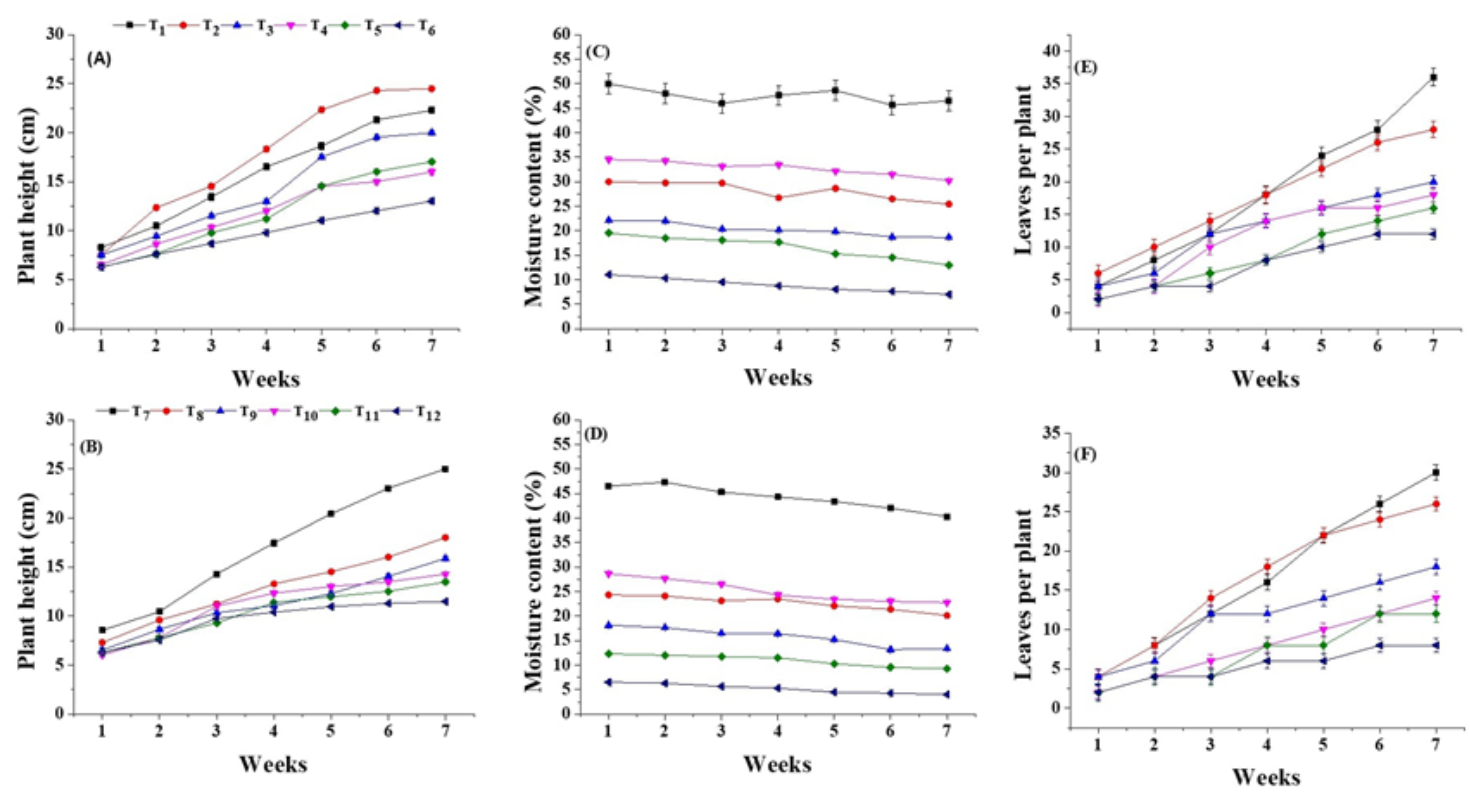

Figure 2. Impact of outside, inside temperature, soil types and water levels against duration of treatment on Plant height (A, B) Moisture content $(C, D)$, Leaves per plant $(E, F)$. Data represented with mean $\pm S D$ on error bar of each treatment against weeks

Leaves per plant also showed significant results with respect to temperature, soil types, water levels and duration of treatment as shown in Table 3. Interaction effect of water levels and temperature was significant $\left(\mathrm{F}_{1,126}=28.602, \mathrm{P}<0.01\right)$ that showed with the increasing temperature plant needed more water to sustain its growth at higher temperature. Interaction effect of soil types and weeks were non-significant $\left(\mathrm{F}_{12}\right.$, $84=0.372, \mathrm{P}=0.534$ ) because properties of different soils with respect to water holding capacity and temperature responses does not depend upon duration of treatments. Regarding leaves per plant under outside temperature regime, $\mathrm{T}_{1}$ showed higher values as compared to others and under inside temperature regime, $\mathrm{T}_{12}$ and $\mathrm{T}_{11}$ showed lower values as compared to other treatments as shown in Figure $2 E, F$.

Number of nodes per plant was also significantly affected by all treatments as shown in Table 3. Interaction effect between temperature and soil types were non-significant $\left(F_{2,126}=0.045, P=0.956\right)$ because every soil has ability to bear higher temperature and maintain their properties. Interaction effects of all factors were non-significant $\left(\mathrm{F}_{12}\right.$, $126=2.104, \mathrm{P}=0.019$ ), which indicated that invasive plant species have ability to maintain their growth in every habitat condition. Number of nodes per plant were decreased with decreasing amount of water and increasing temperature. At both outside and inside temperature with water stress treatments plants have lower number of nodes compared with those under normal water level treatments as shown in Figure 3G, $\mathrm{H}$.

Leaf chlorophyll content was significantly affected by the interaction effect of water levels and weeks $\left(\mathrm{F}_{6,36}=10.764, \mathrm{P}<0.01\right)$. Interaction effects of all other factors were non-significant as show in Table 3. Leaf chlorophyll content value at $\mathrm{T}_{6}, \mathrm{~T}_{11}$ and $\mathrm{T}_{12}$ were decreasing after the $5^{\text {th }}$ week of treatments as shown in Figure 3I, J. This was indicated by the loss of green colour of plant leaves in plants under water stress and high temperature conditions, that is the first indication of plant under stress. 

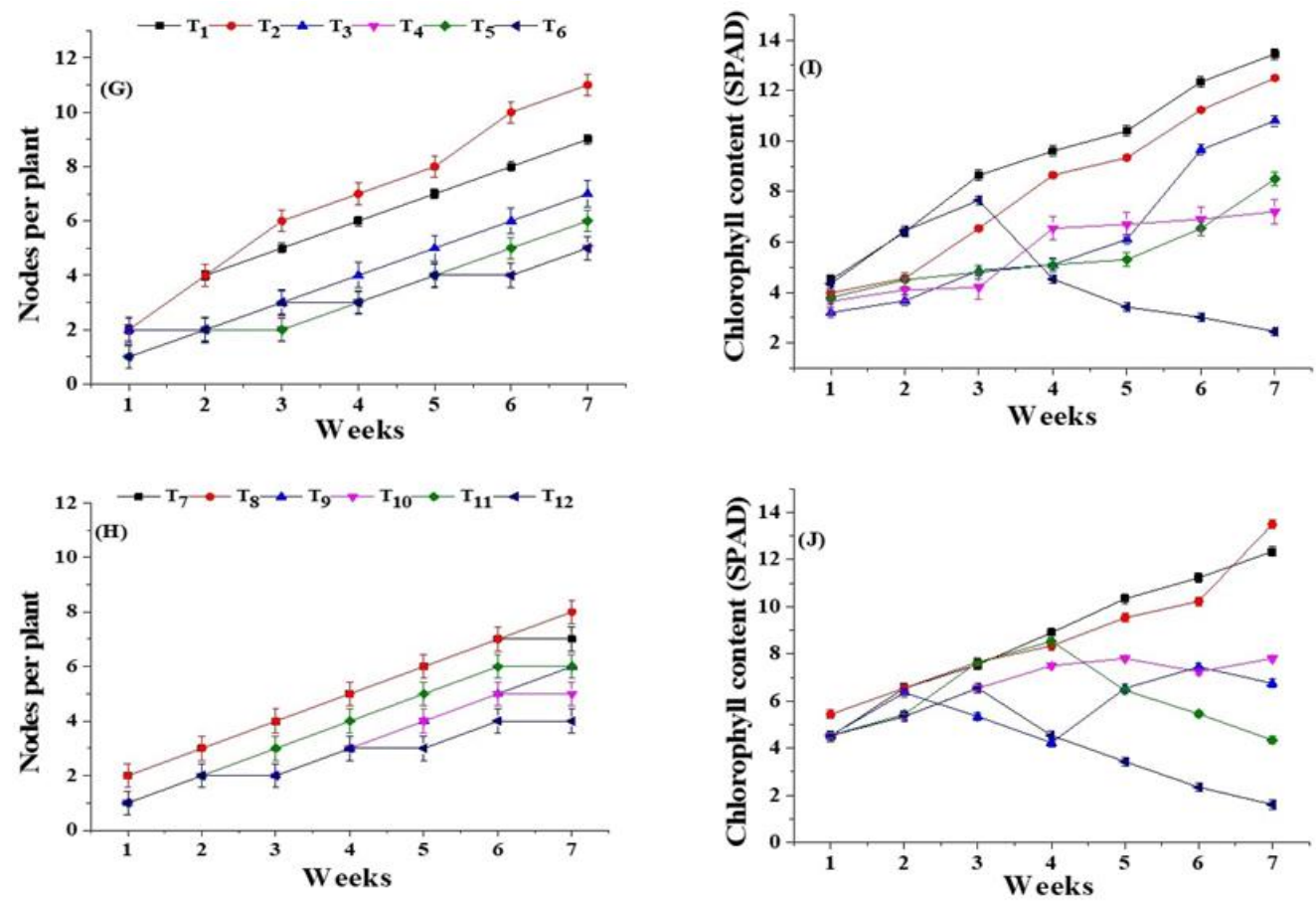

Figure3. Impact of outside, inside temperature, soil types and water levels against duration of treatment on nodes per plant $(G, H)$ Chlorophyll content $(I, J)$. Data represented with mean $\pm S D$ on error bar of each treatment against weeks

Specific leaf area (SLA) was also significantly affected by soil types, water levels and temperature after the $4^{\text {th }}$ and the $8^{\text {th }}$ week of treatments as shown in Tables 4 and 5. SLA of normal soil at $\mathrm{T}_{2}, \mathrm{~T}_{8}$ under normal water at both outside and inside temperature showed a higher value as compared to other soil types as shown in Figure 5U, V. SLA was more affected in all soil types under water stress at inside temperature from the $4^{\text {th }}$ and the $8^{\text {th }}$ week, indicating that plant water requirement increased with its growth development and also with higher temperature. Interaction effect after the $4^{\text {th }}$ week between soil types and temperature were non-significant $\left(\mathrm{F}_{2,18}=2.541, \mathrm{P}=0.10\right)$, but soil types and water levels were significant $\left(\mathrm{F}_{2,18}=68.923, \mathrm{P}<0.01\right)$, which described that every soil has different water holding capacity under same water level conditions. Similar results were found after the $8^{\text {th }}$ week as shown in Table 5. According to the results, Wt can survive under higher temperature, if reasonable amount of water is available or growing medium has ability to hold more water content.

\section{Photosynthetic responses}

Stomatal conductance (gs) gradually decreased during the first four weeks of treatments $\left(\mathrm{F}_{2,18}=18.212, \mathrm{P}<0.01\right)$. Soil types, water levels and temperature $\left(\mathrm{F}_{2,12}=398.988, \mathrm{P}<0.01, \mathrm{~F}_{1,18}=50.536, \mathrm{P}<0.01, \mathrm{~F}_{1,18}=3604.34, \mathrm{P}<0.01\right)$ had a significantly negative effect on stomatal conductance as shown in Figure $4 K$, L. After the $4^{\text {th }}$ to the $8^{\text {th }}$ week all these factors have significant effect on stomatal conductance as shown in Table 5. More negative effect of stomatal conductance was found under water stress treatment at both outside and inside temperature in every soil type as shown in Figure $4 K, L$. These results indicated that $\mathrm{Wt}$ water requirement increased as long as its growth increased. 
All treatments had significant effect on photosynthesis after the $4^{\text {th }}$ and the $8^{\text {th }}$ week of treatment imposition as shown in Tables 4 and 5 . Photosynthesis of $\mathrm{T}_{6}, \mathrm{~T}_{11}$ and $\mathrm{T}_{12}$ were low values as compared to other treatments as shown in Figure 4M, $N$.

Table 4. Analysis of variance after four weeks of treatment against physiological traits

\begin{tabular}{c|c|c|c|c|c|c}
\hline Response & gs & $\mathbf{P}_{\mathbf{N}}$ & $\mathbf{T r}$ & WUE & Wp & SLA \\
\hline Soil type & $398.988^{* *}$ & $851.996^{* *}$ & $81.822^{* *}$ & $413.981^{* *}$ & $117.474^{* *}$ & $84.023^{* *}$ \\
Temperature & $50.536^{* *}$ & $1038.554^{* *}$ & $428.889^{* *}$ & $235.735^{* *}$ & $63.027^{* *}$ & $30.160^{* *}$ \\
Water level & $3604.346^{* *}$ & $3673.937^{* *}$ & $525.208^{* *}$ & $1461.600^{* *}$ & $695.230^{* *}$ & $440.059^{* *}$ \\
Soil Type * Temperature & 5.856 & $153.133^{* *}$ & 2.605 & $111.120^{* *}$ & $8.093^{*}$ & 2.541 \\
Soil Type * Water level & $25.182^{* *}$ & $229.787^{* *}$ & $52.050^{* *}$ & $145.823^{* *}$ & $103.565^{* *}$ & $68.923^{* *}$ \\
Temperature * Water level & $776.286^{* *}$ & $41.521^{* *}$ & $36.141^{* *}$ & $121.644^{* *}$ & $46.066^{* *}$ & 4.142 \\
Soil Type * Temperature* Water level & $18.212^{* *}$ & $61.855^{* *}$ & $30.585^{* *}$ & $16.121^{* *}$ & $17.914^{* *}$ & $9.146^{*}$ \\
\hline
\end{tabular}

Main and interactive effects (F-values) of water levels, temperature and soil type on the physiological traits of Wedelia trilobata after four weeks of treatments. ** and $*$ indicate a significant level at $\mathrm{P}<0.01$ and $\mathrm{P}<0.05$. gs: stomatal conductance, $\mathrm{P}_{\mathrm{N}}$ : photosynthetic rate, Tr: transpiration, WUE: water use efficiency, Wp: water potential and SLA: specific leaf area

Table 5. Analysis of variance after eight weeks of treatment against physiological traits

\begin{tabular}{c|c|c|c|c|c|c}
\hline Response & gs & $\mathbf{P}_{\mathbf{N}}$ & $\mathbf{T r}$ & WUE & Wp & SLA \\
\hline Soil type & $630.385^{* *}$ & $1332.963^{* *}$ & $95.091^{* *}$ & $748.037^{* *}$ & .050 & $109.562^{* *}$ \\
Temperature & $472.724^{* *}$ & $216.031^{* *}$ & $59.751^{* *}$ & $62.306^{* *}$ & .519 & $82.174^{* *}$ \\
Water level & $6820.402^{* * *}$ & $6841.689^{* *}$ & $745.959^{* *}$ & $2771.657^{* *}$ & .030 & $744.589^{* *}$ \\
Soil Type * Temperature & $18.735^{* *}$ & $55.197^{* *}$ & $22.195^{* *}$ & $80.906^{* *}$ & .252 & 3.019 \\
Soil Type * Water level & $124.874^{* *}$ & $33.102^{* *}$ & 5.083 & $41.249^{* *}$ & .087 & $66.032^{* *}$ \\
Temperature * Water level & $340.335^{* *}$ & $178.361^{* *}$ & .813 & $176.575^{* *}$ & .068 & 1.814 \\
Soil Type * temperature* Water level & $29.152^{* *}$ & $8.756^{*}$ & $30.527^{* *}$ & $34.035^{* *}$ & .260 & .259 \\
\hline
\end{tabular}

Main and interactive effects (F-values) of water levels, temperature and soil types on the physiological traits of Wedelia trilobata after eight weeks of treatments. $* *$ and $*$ indicates a significant level at $\mathrm{P}<0.01$ and $\mathrm{P}<0.05$. gs: stomatal conductance, $\mathrm{P}_{\mathrm{N}}$ : photosynthetic rate, Tr: transpiration, WUE: water use efficiency, Wp: water potential and SLA: specific leaf area

Temperature, soil types and water level had a significant effect on transpiration $(\mathrm{Tr})$ of Wt $\left(\mathrm{F}_{1,18}=428.88, \mathrm{P}<0.01, \mathrm{~F}_{2,12}=81.822, \mathrm{P}<0.01, \mathrm{~F}_{1,18}=525.208, \mathrm{P}<0.01\right)$, after 4 weeks of treatment imposition. Transpiration of Wt was decreased with high temperature along with water stress at both outside and inside temperature as shown in Figure $4 O, P$. After 8 weeks of treatment imposition transpiration was decreased significantly more at $\mathrm{T}_{6}, \mathrm{~T}_{11}$ and $\mathrm{T}_{12}$ as compared to other treatments. Interaction effect of soil types, temperature and water levels had a significant effect on transpiration as shown in Tables 4 and 5.

Water use efficiency (WUE) was also negatively affected by increasing temperature and decreasing water availability in every soil types as shown in Figure $5 Q, R$. After the $4^{\text {th }}$ and the $8^{\text {th }}$ week of treatments temperature, soil types and water levels had a significant effect on water use efficiency as show in Tables 4 and 5. WUE were increased from the $4^{\text {th }}$ to the $8^{\text {th }}$ week under normal water level in nutrient soil and normal soil at both outside and inside temperature. While under water stress level in sandy soil at outside and in normal soil and sandy soil at inside temperature, WUE were decreased because stomatal closure and increased transpiration. 

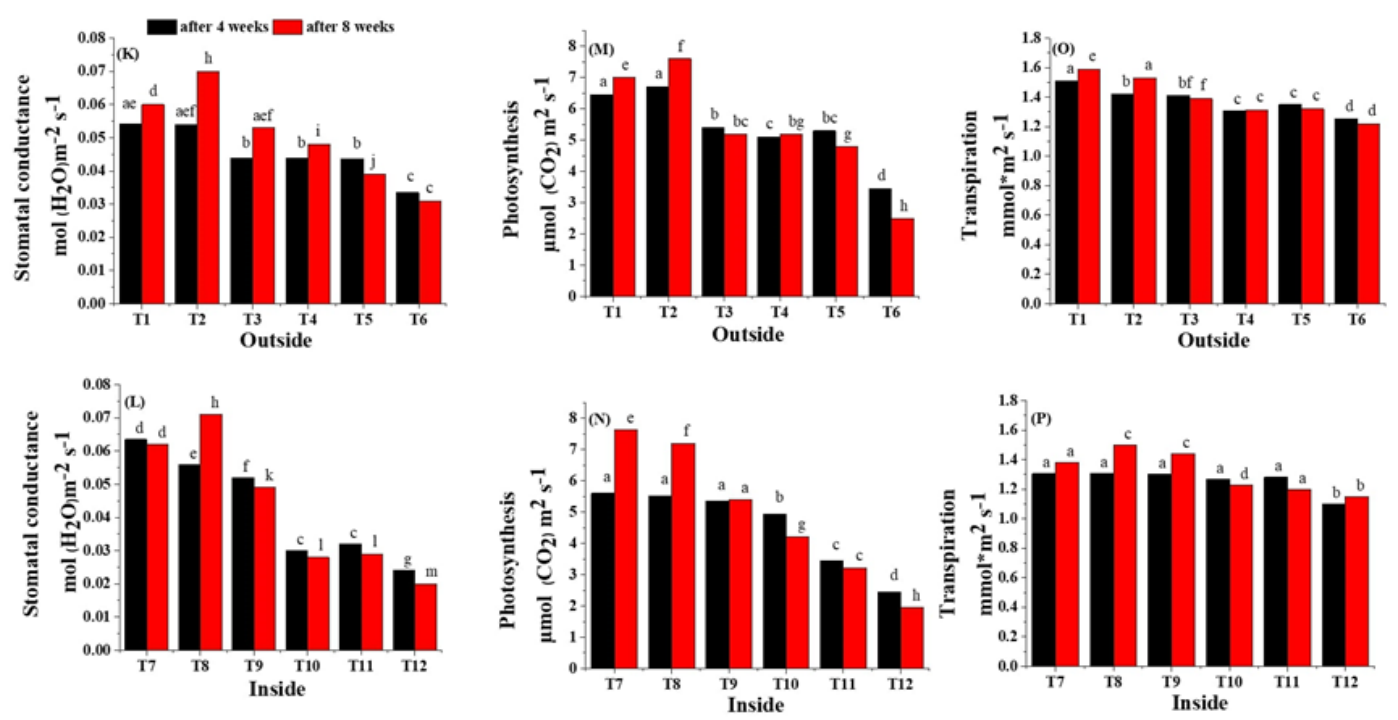

Figure 4. Impact of water levels, temperature and soil types on stomatal conductance $(K, L)$, photosynthesis $(M, N)$ and transpiration $(O, P)$ of Wedelia trilobata after the $4^{\text {th }}$ and the $8^{\text {th }}$ week of treatments. Different letter indicates the significant difference $P<0.05$, according to Tukey

test.
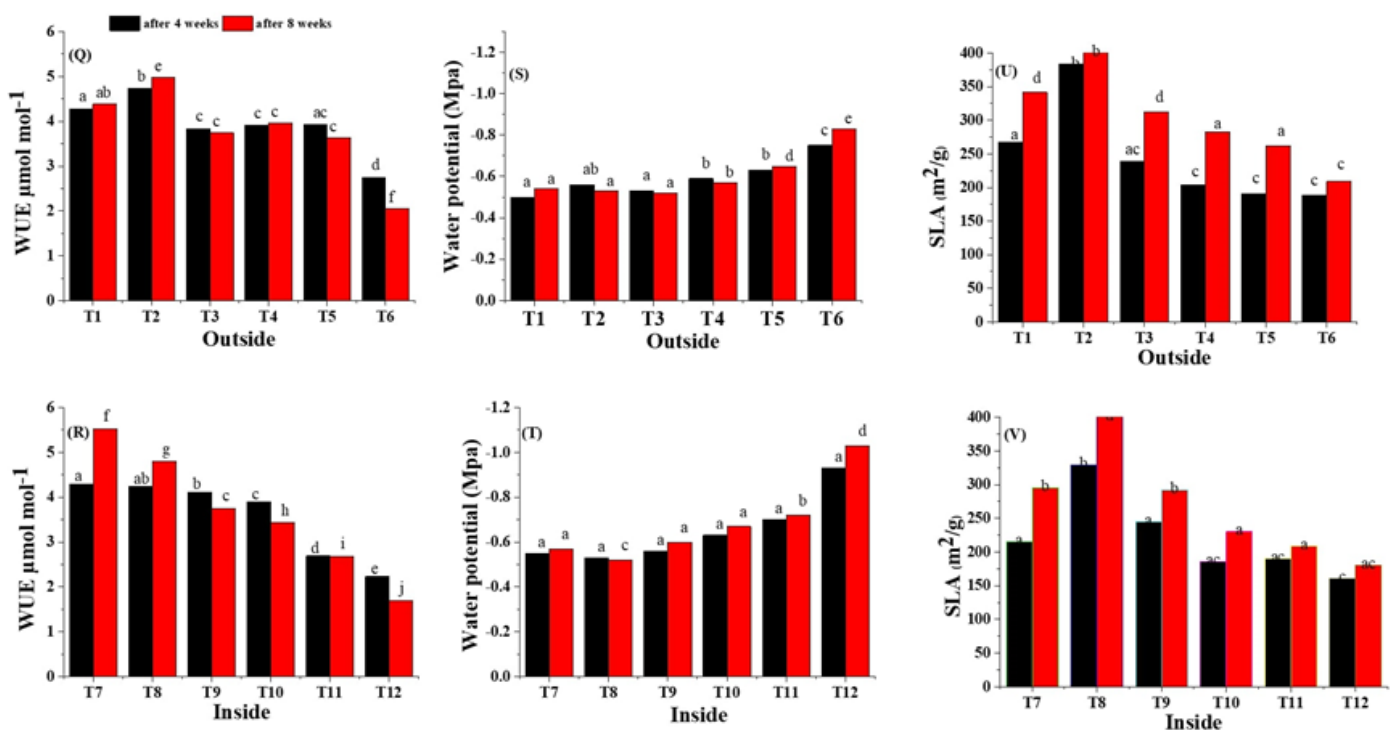

Figure 5. Impact of water levels, temperature and soil types on WUE $(Q, R)$ water potential $(S$, $T)$ and SLA $(U, V)$ of Wedelia trilobata after the $4^{\text {th }}$ and the $8^{\text {th }}$ week of treatments. Different letter indicates the significant difference $P<0.05$, according to Tukey test. WUE: water use efficiency, SLA: specific leaf area

\section{Water status}

After 4 weeks of treatment imposition water potential (Wp) was significantly affected by soil types, temperature and water level as shown in Table 4. Water potential of all soil types under water stress level at both outside and inside temperature were decreased significantly as shown in Figure $5 S$, $T$. These significant results indicated that Wt was facing difficulty to survive under these habitat conditions. After 8 weeks of treatment 
imposition $\mathrm{Wp}$ was non-significant with soil types and water levels $\left(\mathrm{F}_{2,12}=0.05, \mathrm{P}=0.22\right.$, $\left.\mathrm{F}_{1,18}=0.03, \mathrm{P}=0.475\right)$, but significant effect of temperature $\left(\mathrm{F}_{1,18}=0.519, \mathrm{P}<0.01\right)$ was observed. After the $8^{\text {th }}$ week non-significant results indicated that for Wt it took the first four weeks to cope with habitat conditions and after the $4^{\text {th }}$ week due to strong ability of Wt to tolerate all types environmental conditions it maintained steady growth.

\section{Discussion}

\section{Effect of temperature, water stress and different soil types on physiological traits of Wt}

Physiological traits that were considered in this study have often been described among characteristics that may take part in invasive plants development and consequently improve plants growth and enhance invasiveness. In this regard higher photosynthetic rate and morphological traits, that were connected with plant growth development and also with the plant invasiveness (Quinet et al., 2015; Van Kleunen et al., 2010). Especially in high temperature habitats where reasonable amount of water content is needed to maximize photon (Čuda et al., 2014). Under these experiment results SLA, plant height, number of leaves per plant and number of nodes per plant increased under normal water at inside and outside temperature in all soil types with the increasing duration of the treatments as shown in Figure $2 A-D$. This indicated that $\mathrm{Wt}$ has potential to tolerate higher temperature under favourable environmental conditions. Therefore, in the future due to global warming and urbanization there is some possibility that Wt will grow faster in these habitats (Song et al., 2012). Similarly, $\mathrm{P}_{\mathrm{N}}, \mathrm{g}_{\mathrm{s}}$, $\mathrm{Tr}$ and WUE decreased with increasing temperature under water stress at both outside and inside temperature after 4 and 8 weeks as shown Tables 4 and 5 in every soil type. The treatments $\mathrm{T}_{6}, \mathrm{~T}_{11}$, and $\mathrm{T}_{12}$ had lesser growth rate and photosynthetic traits, that indicated Wt was suffering with high temperature stress due to shortage of water as shown in Figures 2 and 4. Soil properties were also played an important role for the successful invasion under water fluctuation and temperature variations (Fang et al., 2016). In sandy soil Wt was suffering due to less water holding capacity at high temperature, similar result was observed in normal soil at inside temperature condition because with the passage of time plant water requirement was increasing (Azeem et al., 2017), but due to insufficient amount of water Wt was suffering. Soil moisture plays an important role in the survival of invasive plant species at high temperature (Song, 2017).

Nutrient soil has better effect on plant growth at both inside and outside temperature along with water stress level due to its better water holding capacity. This allowed Wt to cope with these habitat conditions and it developed better growth. Leaf chlorophyll content at the beginning of the treatments were increasing in every treatment but after the $3^{\text {rd }}$ and the $4^{\text {th }}$ week of the treatments, leaf chlorophyll content at $T_{6}, T_{11}$ and $T_{12}$ were decreasing as shown in Figure 3I, J. Leaf chlorophyll content depends upon sunlight and also the amount of water available for photosynthesis (Song, 2017), which supports our results that leaf chlorophyll content was decreasing under lower photosynthetic rate and under lower water potential (Song et al., 2010).

\section{Invasive potential}

Phenotypic plasticity allows invasive plant species to grow and expand in low resources and heterogeneous habitats (Richards et al., 2006). It has been reported that phenotypic plasticity is the characteristic that promotes invasiveness (Gioria et al., 
2014). In this study growth development were tested under different environmental factors. We observed that physiological traits such as SLA, lower gs, stable $\mathrm{P}_{\mathrm{N}}$, Tr and adjustable $\mathrm{Wp}$ enable $\mathrm{Wt}$ to grow well in different environmental habitats. This could be the best strategy for survival under these habitat conditions (Rahlao et al., 2010). Moreover, Wt is known as fast spreading through nonsexual propagation (clonal growth). Once established in plantation Wt can also grow into a compressed groundcover and avert the revival of native plant species (Song et al., 2010). Macanawai, 2013 and Saptiningsih et al., 2019 reported that Wt can bear higher temperature, water stress and grow in every soil medium that was also confirmed in this study. According to these findings Wt is able to maintain growth development and reproduction within unfavourable conditions, which proposed that the strategy used by Wt for invasion success was very similar to the jack, trades scenario (Richards et al., 2006).

In this study we acknowledged physiological traits connected to temperature and water stress tolerance with different soil types that could indicate high phenotypic plasticity may confer competitive advantages of these invasive plant species. In metaanalysis (Van Kleunen et al., 2015) it was reported that invasive plant species had complex values for several valuable constraints of plant physiology such as $\mathrm{P}_{\mathrm{N}}$, WUE, leaf area, and SLA compared to native plant species. However, the competitive properties of native plant species compared with invasive plant species depend on the environmental resources (Gioria et al., 2014). Many researchers have described that invasive plant species were better contestants in water stress, with different soil textures and higher temperature regimes than native plant species, because they have expressively higher tolerance ability (Gioria et al., 2014; van Kleunen et al., 2011). In this regard studies comparing different plant species with the same family of $\mathrm{Wt}$, could help us to recognize and predict future invasions. In addition, precise experiments under different environmental conditions i.e. temperature and water stress to examine the functional traits among Asteraceae family plants and comparing their physiological traits involved to predict the future trends of invasive species in presently invaded and potentially susceptible countries. Furthermore, future change in climate are possible to affect local, regional moisture, temperature and invasion success of Wt and may aid its spread effectively under future environmental conditions.

\section{Conclusion}

Our study confirmed that higher environmental resource accessibility (water, soil type and temperature) enhanced growth of $\mathrm{Wt}$, furthermore under water stress and high temperature in normal soil and sandy soil, the growth of Wt was decreased. Wt is likely to become more aggressive in the future upcoming heat and water stress conditions. In a long-term evaluation process Wt developed an adaptive strategy to cope with high temperature and water stress in every soil medium. These facts are playing an important role in its management and control. Based on our finding we suggested that managers plan to target areas that have higher precipitation and ambient temperature to remove seedling from that places where Wt performed well. In addition, future study could be done by considering its native congener Wedelia chinensis along with these environmental factors under competition experiment. Therefore, investigating the growth development under competition along with these environmental factors could give us more understanding for the invasion success of Wt under these environmental conditions. 
Acknowledgment. This work was supported by the State Key Research Development Program of China (2017YFC1200100), the National Natural Science Foundation of China (31971427, 31570414, and 31770446), the Priority Academic Program Development of Jiangsu Higher Education Institutions (PAPD), and the Jiangsu Collaborative Innovation Center of Technology and Material of Water Treatment.

\section{REFERENCES}

[1] Abatzoglou, J. T., Kolden, C. A. (2011): Climate change in western US deserts: potential for increased wildfire and invasive annual grasses. - Rangeland Ecology \& Management 64: 471-478.

[2] Adamowski, W., Tokarska-Guzik, B. (2008): Balsams on the Offensive: The Role of Planting in the Invasion of Impatiens Species. - In: Tokarska-Guzik B. et al. (eds.) Plant Invasions: Human Perception, Ecological Impacts and Management. Backhuys Publishers, Leiden, pp. 57-70.

[3] Azeem, A., Wu, Y., Javed, Q., Xing, D., Ullah, I., Kumi, F. (2017): Response of okra based on electrophysiological modeling under salt stress and re-watering. - Bioscience Journal 33.

[4] Azeem, A., Sun, J., Javed, Q., Jabran, K., Du, D. (2020): The effect of submergence and eutrophication on the trait's performance of Wedelia trilobata over its congener native Wedelia chinensis. - Water 12: 934.

[5] Baker, H. G. (1974): The evolution of weeds. - Annual Review of Ecology and Systematics 5: 1-24.

[6] Blossey, B., Notzold, R. (1995): Evolution of increased competitive ability in invasive nonindigenous plants: a hypothesis. - Journal of Ecology 83: 887-889.

[7] Callaway, R. M., Aschehoug, E. T. (2000): Invasive plants versus their new and old neighbors: a mechanism for exotic invasion. - Science 290: 521-523.

[8] Callaway, R. M., Thelen, G. C., Rodriguez, A., Holben, W. E. (2004): Soil biota and exotic plant invasion. - Nature 427: 731.

[9] Colautti, R. I., Grigorovich, I. A., Macisaac, H. J. (2006): Propagule pressure: a null model for biological invasions. - Biological Invasions 8: 1023-1037.

[10] Čuda, J., Skálová, H., Janovský, Z., Pyšek, P. (2014): Habitat requirements, short-term population dynamics and coexistence of native and invasive Impatiens species: a field study. - Biological Invasions 16: 177-190.

[11] Dai, Z.-C., Fu, W., Qi, S.-S., Zhai, D.-L., Chen, S.-C., Wan, L.-Y., Huang, P., Du, D.-L. (2016): Different responses of an invasive clonal plant Wedelia trilobata and its native congener to gibberellin: implications for biological invasion. - Journal of Chemical Ecology 42: 85-94.

[12] Ebeling, S. K., Hensen, I., Auge, H. (2008): The invasive shrub Buddleja davidii performs better in its introduced range. - Diversity and Distributions 14: 225-233.

[13] Fang, X., Zhou, G., Li, Y., Liu, S., Chu, G., Xu, Z., Liu, J. (2015): Warming effects on biomass and composition of microbial communities and enzyme activities within soil aggregates in subtropical forest. - Biology and Fertility of Soils 52: 353-365.

[14] Fang, X., Zhou, G., Li, Y., Liu, S., Chu, G., Xu, Z., Liu, J. (2016): Warming effects on biomass and composition of microbial communities and enzyme activities within soil aggregates in subtropical forest. - Biology and Fertility of Soils 52: 353-365.

[15] Gioria, M., Osborne, B. A. (2014): Resource competition in plant invasions: emerging patterns and research needs. - Frontiers in Plant Science 5: 501.

[16] Jacquemart, A.-L., Somme, L., Colin, C., Quinet, M. (2015): Floral biology and breeding system of Impatiens balfourii (Balsaminaceae): an exotic species in extension in temperate areas. - Flora-Morphology, Distribution, Functional Ecology of Plants 214: 7075 . 
[17] Javed, Q., Sun, J., Azeem, A., Ullah, I., Huang, P., Kama, R., Jabran, K., Du, D. (2019): The enhanced tolerance of invasive alternanthera philoxeroides over native species under salt-stress in china. - Applied Ecology and Environmental Research 17: 14767-14785.

[18] Keane, R. M., Crawley, M. J. (2002): Exotic plant invasions and the enemy release hypothesis. - Trends in Ecology \& Evolution 17: 164-170.

[19] Legault Ii, R., Zogg, G. P., Travis, S. E. (2018): Competitive interactions between native Spartina alterniflora and non-native Phragmites australis depend on nutrient loading and temperature. - PloS One 13: e0192234.

[20] Lorenzo, P., González, L., Reigosa, M. J. (2010): The genus Acacia as invader: the characteristic case of Acacia dealbata Link in Europe. - Annals of Forest Science 67: 101.

[21] Middleton, E. L., Bever, J. D. (2012): Inoculation with a native soil community advances succession in a grassland restoration. - Restoration Ecology 20: 218-226.

[22] Moravcova, L., Pyšek, P., Jarošík, V., Havlíčková, V., Zákravský, P. (2010): Reproductive characteristics of neophytes in the Czech Republic: traits of invasive and non-invasive species. - Preslia 82: 365-390.

[23] Pairon, M., Petitpierre, B., Campbell, M., Guisan, A., Broennimann, O., Baret, P. V., Jacquemart, A.-L., Besnard, G. (2010): Multiple introductions boosted genetic diversity in the invasive range of black cherry (Prunus serotina; Rosaceae). - Annals of Botany 105: 881-890.

[24] Qi, S.-S., Dai, Z.-C., Miao, S.-L., Zhai, D.-L., Si, C.-C., Huang, P., Wang, R.-P., Du, D.L. (2014): Light limitation and litter of an invasive clonal plant, Wedelia trilobata, inhibit its seedling recruitment. - Annals of Botany 114: 425-433.

[25] Quinet, M., Descamps, C., Coster, Q., Lutts, S., Jacquemart, A.-L. (2015): Tolerance to water stress and shade in the invasive Impatiens parviflora. - International Journal of Plant Sciences 176: 848-858.

[26] Rahlao, S. J., Esler, K. J., Milton, S. J., Barnard, P. (2010): Nutrient addition and moisture promote the invasiveness of crimson fountain grass (Pennisetum setaceum). Weed Science 58: 154-159.

[27] Richards, C. L., Bossdorf, O., Muth, N. Z., Gurevitch, J., Pigliucci, M. (2006): Jack of all trades, master of some? On the role of phenotypic plasticity in plant invasions. - Ecology Letters 9: 981-993.

[28] Saptiningsih, E., Dewi, K., Santosa, S., Purwestri, Y. A. (2019): Clonal integration of the invasive plant Wedelia trilobata (L.) Hitch in stress of flooding type combination. International Journal of Plant Biology 10.

[29] Schweiger, O., Biesmeijer, J. C., Bommarco, R., Hickler, T., Hulme, P. E., Klotz, S., Kühn, I., Moora, M., Nielsen, A., Ohlemüller, R. (2010): Multiple stressors on biotic interactions: how climate change and alien species interact to affect pollination. Biological Reviews 85: 777-795.

[30] Song, L., Chow, W. S., Sun, L., Li, C., Peng, C. (2010): Acclimation of photosystem II to high temperature in two Wedelia species from different geographical origins: implications for biological invasions upon global warming. - Journal of Experimental Botany 61: 4087-4096.

[31] Song, U. (2017): Temperature-dependent performance of competitive native and alien invasive plant species. - Acta Oecologica 84: 8-14.

[32] Song, U., Mun, S., Ho, C.-H., Lee, E. J. (2012): Responses of two invasive plants under various microclimate conditions in the Seoul metropolitan region. - Environmental Management 49: 1238-1246.

[33] Sun, J., Javed, Q., Azeem, A., Ullah, I., Saifullah, M., Kama, R., Du, D. (2019): Fluctuated water depth with high nutrient concentrations promote the invasiveness of Wedelia trilobata in Wetland. - Ecology and Evolution. https://doi.org/10.1002/ece3.5941. 
[34] Teitel, M., Atias, M., Barak, M. (2010): Gradients of temperature, humidity and CO2 along a fan-ventilated greenhouse. - Biosystems Engineering 106: 166-174.

[35] Ureña-Sánchez, R., Callejón-Ferre, Á. J., Pérez-Alonso, J., Carreño-Ortega, Á. (2012): Greenhouse tomato production with electricity generation by roof-mounted flexible solar panels. - Scientia Agricola 69: 233-239.

[36] Valiño, V., Rasheed, A., Tarquis, A. M., Perdigones, A. (2014): Effect of increasing temperatures on cooling systems. A case of study: European greenhouse sector. Climatic Change 123: 175-187.

[37] Van Der Heijden, M. G., Bardgett, R. D., Van Straalen, N. M. (2008): The unseen majority: soil microbes as drivers of plant diversity and productivity in terrestrial ecosystems. - Ecology Letters 11: 296-310.

[38] Van Der Putten, W. H. (2010): Impacts of soil microbial communities on exotic plant invasions. - Trends in Ecology \& Evolution 25: 512-519.

[39] Van Kleunen, M., Weber, E., Fischer, M. (2010): A meta-analysis of trait differences between invasive and non-invasive plant species. - Ecology Letters 13: 235-245.

[40] Van Kleunen, M., Schlaepfer, D. R., Glaettli, M., Fischer, M. (2011): Preadapted for invasiveness: do species traits or their plastic response to shading differ between invasive and non-invasive plant species in their native range? - Journal of Biogeography 38: 12941304.

[41] Van Kleunen, M., Dawson, W., Essl, F., Pergl, J., Winter, M., Weber, E., Kreft, H., Weigelt, P., Kartesz, J., Nishino, M. (2015): Global exchange and accumulation of nonnative plants. - Nature 525: 100.

[42] Wang, R. L., Zeng, R. S., Peng, S. L., Chen, B. M., Liang, X. T., Xin, X. W. (2011): Elevated temperature may accelerate invasive expansion of the liana plant Ipomoea cairica. - Weed Research 51: 574-580.

[43] Weber, E., Sun, S.-G., Li, B. (2008): Invasive alien plants in China: diversity and ecological insights. - Biological Invasions 10: 1411-1429.

[44] Will, R. E., Wilson, S. M., Zou, C. B., Hennessey, T. C. (2013a): Increased vapor pressure deficit due to higher temperature leads to greater transpiration and faster mortality during drought for tree seedlings common to the forest-grassland ecotone. New Phytologist 200: 366-374.

[45] Will, R. E., Wilson, S. M., Zou, C. B., Hennessey, T. C. (2013b): Increased vapor pressure deficit due to higher temperature leads to greater transpiration and faster mortality during drought for tree seedlings common to the forest-grassland ecotone. New Phytologist 200: 366-374.

[46] Willits, D. (2003): Cooling fan-ventilated greenhouses: a modelling study. - Biosystems Engineering 84: 315-329.

[47] Xiaoming, D., Changji, Z. (2008): Test and measurement of solar visible radiation transmittance of greenhouse glazing. - Transactions of the Chinese Society of Agricultural Engineering 2008(8).

[48] Xu, Z. Z., Zhou, G. S. (2006): Combined effects of water stress and high temperature on photosynthesis, nitrogen metabolism and lipid peroxidation of a perennial grass Leymus chinensis. - Planta 224: 1080-1090.

[49] Zheng, Y.-L., Feng, Y.-L., Liu, W.-X., Liao, Z.-Y. (2009): Growth, biomass allocation, morphology, and photosynthesis of invasive Eupatorium adenophorum and its native congeners grown at four irradiances. - Plant Ecology 203: 263-271. 